DOI:10.2151/jmsj.87.459

\title{
Nighttime Precipitation Induced by a Synoptic-scale Convergence in the Central Tibetan Plateau
}

\author{
Kenichi UENO, Saneyuki TAKANO ${ }^{1}$ \\ Graduate School of Life and Environmental Sciences, University of Tsukuba, Tsukuba, Japan \\ and \\ Hiroyuki KUSAKA \\ Center for Computational Sciences, University of Tsukuba, Tsukuba, Japan \\ (Manuscript received 5 June 2008, in final form 26 February 2009)
}

\begin{abstract}
In the 1998 monsoon season, precipitation from midnight through early morning was frequently observed in the central Tibetan Plateau (TP). It occurred on several successive days and tended to be accompanied by low-level easterly winds. Global Energy and Water Cycle Experiment (GEWEX) Asian Monsoon Experiment (GAME) reanalysis data also showed easterly component winds as a part of anti-cyclonic circulations in the northeastern plateau systematically occurring with a prevailing synoptic scale trough at around $100^{\circ} \mathrm{E}$ in the mid-latitudes. A numerical simulation by the Weather Research and Forecasting (WRF) model with a resolution of $15 \mathrm{~km}$ reproduced the development of a convergence flow over the central TP, and corresponding zonal cloud formation was confirmed by METEOSAT-IR images. The simulation results indicated that the precipitation system was developed through with dissipating nighttime low-level convective instability by low-level convergence flows, and sonde observations confirmed the existence of an instability layer. Sensitivity experiments revealed that the convergence pattern over the central TP was produced by the dynamical stagnation effect of the plateau topography to the northwesterly general flows from the mid-latitudes. Many former studies have explained nocturnal precipitation in monsoon Asia as a part of an orographically induced diurnal variation. However, this study characterized the nighttime precipitation over the central TP due to synoptic-scale convergence. Two reasons are given to explain the substantial precipitation enhancement in the night. One is the daytime thermal convections that depend strongly on the topography, which dissipate synoptic-scale convergences zone, and the other is the low-level moistening after the maturing of the monsoon season to increase nighttime convective instability.
\end{abstract}

\section{Introduction}

Nighttime precipitation over land occurs frequently during the monsoon season in Asia near the large-scale mountains. The precipitation zone

Corresponding author: Kenichi Ueno, Graduate School of Life and Environmental Sciences University of Tsukuba, Tennodai 1-1-1, Tsukuba, Ibaraki, Ibaraki 305-8577, Japan.

E-mail: kenueno@sakura.cc.tsukuba.ac.jp

1. Present affiliation: Mizuho Information \& Research Institute, Inc.

(C) 2009, Meteorological Society of Japan along the southern foothills of the Himalayas in Nepal occurs primarily in the nighttime (e.g., Higuchi 1977; Bhatt and Nakamura 2005). Barros and Lang (2003) explained the mechanism of the nighttime precipitation as stagnation of monsoon flows at the foot of the mountains due to a lack of nighttime valley winds. In Bangladesh, Kataoka and Satomura (2005) attributed night-to-early morning precipitation on a convergence between southwest monsoon and squall lines propagated from the Megalaya Plateau. In northern Thailand, Satomura (2000) demonstrated that nighttime precipitation 
was induced by the propagation of a precipitation system initiated at the Dawna Range, stretching latitudinally along the west border of Thailand. Such eastward propagation of a precipitation system from the mountain range had been reported in the lee of the Rocky Mountains (Tripoli and Cotton 1989; Tucker and Crook 1999). Namely, the cause of the nighttime precipitation is mostly attributed to the effects of mountain ranges, and the system also varies depending on the topography and location facing the monsoon circulation. The initiation of the convection interacting with local circulations at the mountains, propagation from the mountain slopes, and convergence with lowlevel monsoon flows have been thought to be particularly important functions enhancing the nighttime precipitation.

Over the Tibetan Plateau (TP), tall cumulous convection frequently develops during the monsoon season (e.g., Uyeda et al. 2001), and released latent heating is attributed to a major source of diabatic heating affecting the progress of the Asian monsoon (e.g., Yanai and Wu 2006). The convective activity over the plateau is induced by strong diurnal variability. Daytime high-level clouds were prominent according to the $100-300-\mathrm{km}$-scale mountain ranges (Kurosaki and Kimura 2002), and movement of cloud areas from the mountain ridges in the daytime to the valleys in the night was identified in the southern plateau (Fujinami et al. 2005). Ueno et al. (1998) estimated the plateau scale distribution of differences in precipitation amount between day and night using Geostationary Meteorological Satellite (GMS) Infra-Red (IR) image data and revealed that the estimated patterns are affected by the large-scale mountain ranges and valleys on the plateau. Yang (2004) proposed the importance of wetness in the atmosphere for the propagation of the mesoscale convections over the mountain ranges toward lower elevations by numerical experiments. During the monsoon of 1998, a GAME-Tibet project was conducted in the central TP, where multiple precipitation gauges were set in the Naqu basin located $30^{\circ} \mathrm{N} / 90^{\circ} \mathrm{E}$ with altitudes of around $4500 \mathrm{~m}$ above sea level (a.s.1.), shown in Fig. 1, and temporal and spatial variability of precipitation was intensively observed. However, spatially averaged hourly precipitation did not show the clear diurnal changes expected from the convective activity observed by the GMS, and the hourly base precipitation intensity was larger in the middle of the night than that in the evening
(Ueno et al. 2001).

Following the GAME-Tibet project, mechanisms that produce daytime strong convection with light precipitation have been examined on the basis of the points of land-atmosphere interaction. Yamada and Uyeda (2006) pointed out that lighter amounts of diurnal rains in the beginning of the monsoon season were due to the evaporation of precipitation within a drier and deeper subcloud layer. By idealized numerical simulations over a flat highland, Yanama (2008) confirmed a different initial surface condition at dawn by means of wet and dry land successively caused different structures of diurnal cumulous development. The impact of land-surface wetness or vegetation on the initiation of morning convection and successive precipitation activities has also been studied in North America, where the importance of early morning low-level atmospheric conditions has been stressed (e.g., Clark and Arritt 1955; Findell and Eltahir 2003). Furthermore, nighttime precipitation is a key factor in determining surface soil moisture, which is an important initial condition for the start of the successive diurnal development of convection.

Regarding the mechanism of nighttime precipitation in the central TP, Shimizu et al. (2001) clarified that midnight precipitation with intensity of more than $4 \mathrm{~mm} \mathrm{~h}^{-1}$ was provided from the lower stratiform echoes with low-level north-easterlies without the prevalence of a passing synoptic scale westerly disturbance on the Japan Meteorological Agency (JMA) global objective analysis data. This nighttime event was not linked to the development of cumulous convection in the previous evening, and the propagation of precipitation system from the Tanggula or Niencheng-tanggla mountain ranges sandwiching the Naqu basin in the north and south was not identified. During the GAME-Tibet project, night to early morning precipitation was frequently experienced at the Naqu basin, which was also recognized as a relative increase of precipitation after midnight, as shown in Fig. 9b of Ueno et al. (2001). However, the causes have not been thoroughly investigated. In this study, occurrence of the precipitation from midnight to early morning (PME) through a monsoon period in 1998 was examined by a synoptic-scale point of view on the basis of in-situ evidences. The case of PME August 1-2 examined by Shimizu et al. (2001) was treated as a case study to diagnose the mechanisms of lowlevel convergence and instability by numerical experiments. 


\section{Data and methods}

The analysis period was set from June through August 1998 when the GAME-Tibet project was conducted. The precipitation data set is the same as that used in Ueno et al. (2001), in which details of gauge distribution and measurement methods are explained. At first, days with PME events were selected from the hourly precipitation record observed at ten gauge stations located within the Naqu basin (see Fig. 2 and Table 1 in Ueno et al. 2001): WADD, NODA, AQB, AMD-PBL, NPAM, ZURI, MS3543, Naqu-TIP, MS3608, and S-PAM, in which four stations were equipped with weight-type total precipitation gauges. PME is defined as precipitation events occurring between 23:00 and 9:00 local time (LT) to cover the relative increase in the precipitation amount after midnight, as shown in Ueno et al. (2001), where the LT is 6 hours ahead of Universal Time Coordination (UTC). Nighttime precipitation prior to 23:00 LT was excluded to avoid events provided by the cumulous convection during the evening through early night. Most of the precipitation in the Naqu basin fell as rain or hail during the monsoon season (Ueno et al. 2001), but there were some cases of snowfall in the nighttime. The Naqu basin extends in the $100 \mathrm{~km}$ scale with meandering of topography, and one single piece of gauge data is not representative even for the daily average value. To filter the local sporadic precipitation events or under-catch of the solid precipitation, ten gauge station data in the basin were accumulated for 23:00-9:00 LT as a single data point to identify the occurrence of the daily base PME.

The characteristics of the surface wind conditions at the Naqu basin and plateau-scale circulations during the days with PME were clarified by in situ observation data and GAME reanalysis data. For the in situ data, the wind speed and direction were measured at the BJ site by Choi et al. (2004), where $3.5 \mathrm{~m}$ level data of the Automated Weather Station (AWS) were used. The BJ site was located $17 \mathrm{~km}$ southwest of Naqu City with a $10 \mathrm{~km}$ scale flat field, and the location was appropriate for monitoring the surface wind system in all directions. Sonde data at the Amdo site, located about $70 \mathrm{~km}$ north of the BJ site with an altitude at $4,800 \mathrm{~m}$ a.s.1., were used to diagnose the structure of the lower troposphere. The sonde observation was conducted from 0 to 12 UTC at 3-hour intervals, and additional nighttime observations were conducted at
15, 18, and 21 UTC during certain weeks. However, the nighttime observations were not always accompanied by PME. This study selected three profile data at 0 UTC (6:00 LT) and two profile data at 21 UTC (3:00 LT) to diagnose the wind field and stability in the troposphere over the Naqu basin accompanied with the PME. GAME reanalysis data (Yamazaki 2003) was 6-hour-interval data with 0.5 degree grid, where auxiliary sonde data during the GAME intensive observation periods were assimilated except at the Amdo site.

The mechanism of PME through August 1-2 was intensively diagnosed by numerical simulations using Weather Research and Forecast (WRF) model (Skamarock et al. 2005). This event was the same as that in Case 2 in the study by Shimizu et al. (2001), in which the apparent precipitation was observed at midnight with a stratiform radar echo in the Naqu basin. Hourly interval METEOSAT-5 IR images, provided by the European Organization for the Exploitation of Meteorological Satellites, were used to verify the formation of clouds.

Numerical experiments by the WRF Version 2.1.2 model were performed in the domain of Fig. 1 with $15 \mathrm{~km}$ of horizontal resolution and 24 vertical layers. GAME reanalysis data consisted of 6 hours interval with 0.5 degree grids was used to create the initial condition of the atmosphere. On the other hand, to create the surface initial condition,

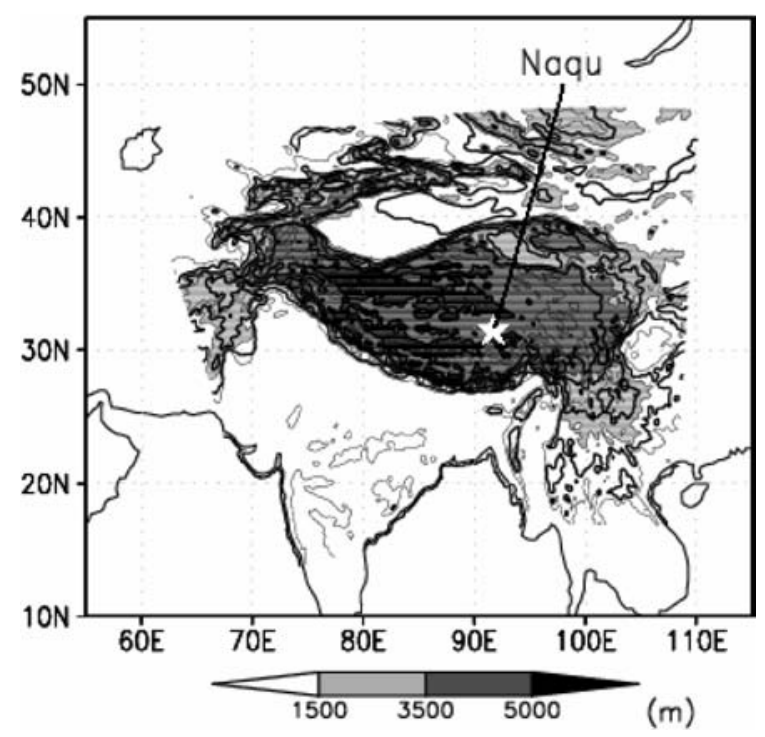

Fig. 1. Tibetan Plateau with the location of Naqu basin and topography in a domain for the numerical simulation. 


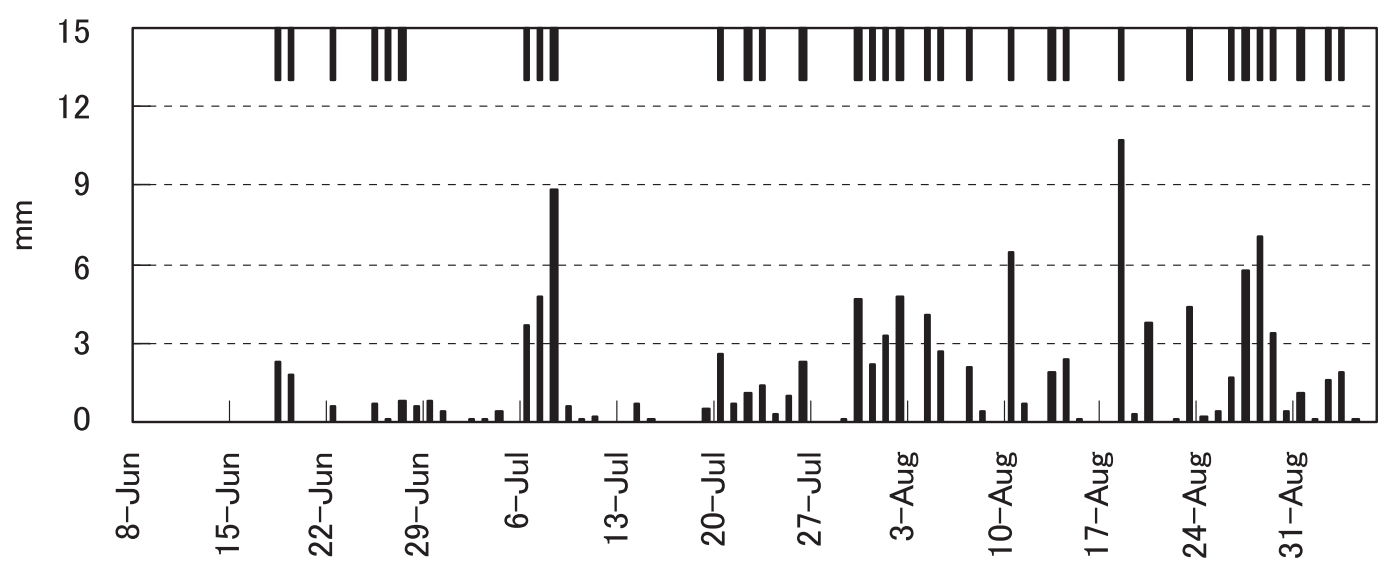

Fig. 2. Time sequence of accumulated precipitation through 23:00-9:00 local time. Days with more than 1 $\mathrm{mm}$ of the PME are marked as bars in the upper section.

NCEP-NCAR reanalysis data (Kalnay et al. 1996) were used because of the lack of the surface data in the GAME reanalysis data set. For the lateral- and top-boundary conditions, GAME reanalysis data was used, which were given at every time step though the linear interpolation on the time and space. Surface fluxes simulated at every time step are used as the bottom boundary condition. In the present simulation, the surface skin temperature is simulated but sea surface temperature is fixed. Kain-Fritsch scheme (Kain and Fritsch 1993) was applied for the convective parameterization, and the Noah land-surface model (Chen and Dudhia 2001) was chosen for surface parameterization. Elevations data by GTOPO30 was 30-second-interval data (U.S. Geological Survey 2000). A numerical simulation (time integration) was conducted from July 31 12:00 UTC for 36 hours, and the simulated results from August 1 12:00 UTC to 2 23:00 UTC were used to diagnose the precipitation system.

\section{Occurrence of PME during the 1998 monsoon season}

Figure 2 shows the time sequence of PME from June 8 to September 5 in 1998. PME occurred on 68 days (76\% of the period) and frequently appeared during the monsoon season. The accumulated PME has occupied $35 \%$ of the total seasonal precipitation, which is not a negligible amount by means of surface water budget. PME with more than $1 \mathrm{~mm}$ occurred on 29 days; such events are marked with bars at the top of Fig. 2 and listed in Table 1. We assigned those days as possible explanations for the mechanism of PME. According to
Table 1. List of the PME with more than $1 \mathrm{~mm} / \mathrm{d}$ of the precipitation amount. Successive days are underlined. Asterisks indicate the prevailing of easterly component winds after midnight.

\begin{tabular}{|c|c|}
\hline June & $18 *, 19 *$ \\
\hline July & $6^{*}, 7^{*}, 8^{*}, 20,22^{*}, 23^{*}, 26^{*}, 30^{*}, 31$ \\
\hline August & $\begin{array}{l}\frac{1,2^{*}}{18,20}, \frac{4^{*}, 5}{23^{*}}, \frac{7,10^{*}, 13,14^{*}, 27^{*}, 28,29}{28}, 31^{*}\end{array}$ \\
\hline September & $\underline{2,3}$ \\
\hline
\end{tabular}

Table 1, PME days tend to appear successively, as shown by underlines. This feature raises one important speculation, namely, that PME does not occur as a part of the diurnal variation but may occur under certain synoptic conditions prevailing for several days.

According to Shimizu et al. (2001), a nighttime precipitation prevailed in the Naqu basin on $\mathrm{Au}-$ gust $1-2$ and was accompanied by low-level easterly winds in the Doppler velocity field obtained using the Velocity Azimuth Display method without remarkable synoptic-scale disturbances on the objective analysis data. To clarify the commonality of the wind system between each PME case, the surface wind direction observed by an AWS at the BJ site was checked for all days shown in the Table 1. We then found that 16 days of PME (marked with an asterisk in Table 1) were accompanied with an easterly component wind that agreed with the case by Shimizu et al. (2001). Figure 3 shows a composite of wind direction changes for those days, indicating that winds from the northeast to the southeast-south clearly prevailed during 2:00-5:00 

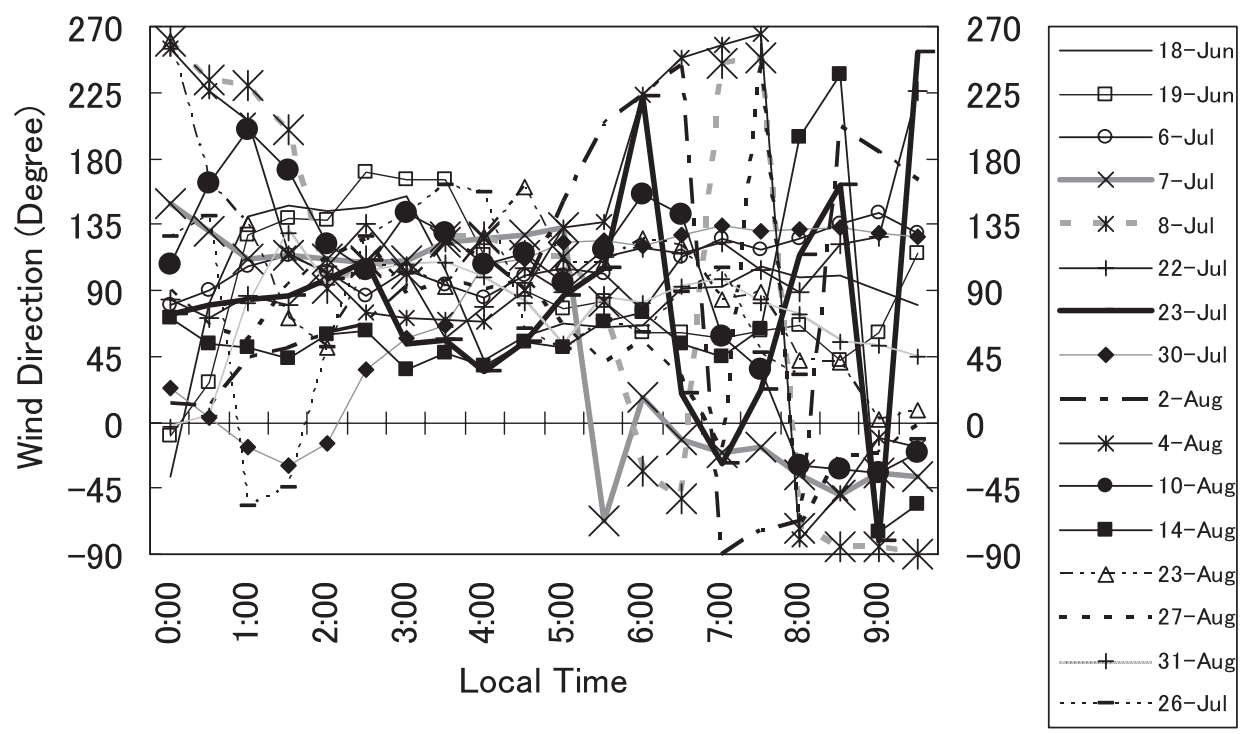

Fig. 3. Composition of wind direction changes at Naqu BJ station through 0:00-9:00 LT for 16 days of PME as marked * in the Table 1.

LT. Easterly wind speeds were less than $4 \mathrm{~m} / \mathrm{s}$ (figure omitted). The wind system in the troposphere was examined using sonde data at the Amdo site. Unfortunately, there were few sonde observations conducted from 2:00-5:00 which prevented the aerological observation of PME. In the PME days listed in Table 1, the observation at 6:00 (3:00) LT occurred 21 (3) times, where easterly component winds were found in the $6(2)$ profiles. Wind and potential temperature profiles for five representative cases are shown in Fig. 4. Lower troposphere was stable in the night, and the easterly winds prevailed below $7 \mathrm{~km}$ a.s.l. (around 1,000 $\mathrm{m}$ thick over the ground surface), similar to an intrusion under the upper thick general flows. The time of sonde observations was not exactly the same with that occurring in PME. However, observational evidences showed that many of the PME cases accompanied easterly low-level flows prevailing over the basin, which were detected by the AWS and sonde data. As large mountain ranges do not exist in the east of the Naqu basin and the wind system was deeper than the local undulations around the Amdo site, the easterly flow seems to be induced not by the local-scale gravity currents from the mountains surrounding the basin but by larger-scale systems that would strongly relate to the mechanism of PME.

To examine the synoptic conditions of PME with easterly flows, $500 \mathrm{hPa}$ geopotential height and wind vector on 16 days, marked with an aster- isk on the Table 1, were composed and compared with the average through the analysis period in Fig. 5. Only the data at 18 UTC (midnight local time) were used. Circulation fields in the north of the TP were largely different between the two. For a composite case of PME (Fig. 5, right), the pressure pattern showed the ridge in the west and trough in the east in the north of $40^{\circ} \mathrm{N}$. The northwesterly flow with the trough approached the northeast of the plateau. A weak southwesterly flow existed at the location of the Naqu basin (around $32^{\circ} \mathrm{N} / 92^{\circ} \mathrm{E}$ ), and an easterly flow appeared in the north of the plateau (around $35^{\circ} \mathrm{N} / 80-92^{\circ} \mathrm{E}$ ). To realize the actual synoptic flow patterns around the TP, five cases of $500 \mathrm{hPa}$ geopotential fields at 18 UTC, with apparent PME and easterly winds at the BJ site, are shown in Fig. 6. All of the cases showed a mid-latitude trough in the northeast or north of TP. It is important that the troughs accompanying anticyclonic circulations in the southwest (marked H in Fig. 6) located over the northern or northeastern part of the central plateau, and the anticyclonic circulation were causing an easterly flow over the plateau. Those synoptic patterns prevailed on adjacent days. In addition, the synoptic patterns in the night without precipitation did not indicate the specific location of a trough and easterly flows over the TP (figures omitted). Namely, low-level easterly flow observed at Naqu was due to synoptic scale anticyclonic circulation over the 


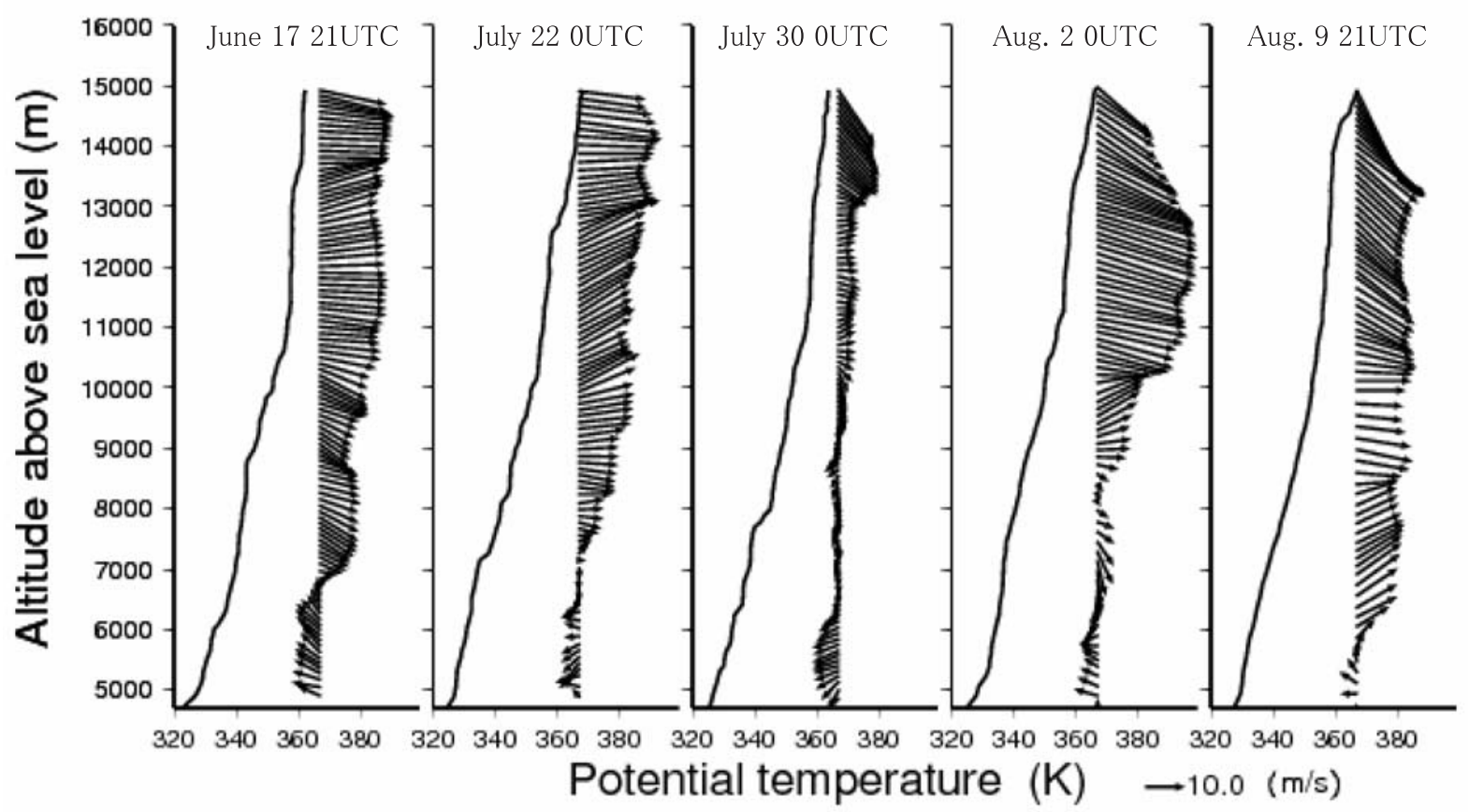

Fig. 4. Vertical distribution of horizontal wind vector and potential temperatures on five representative days observed at Amdo site.
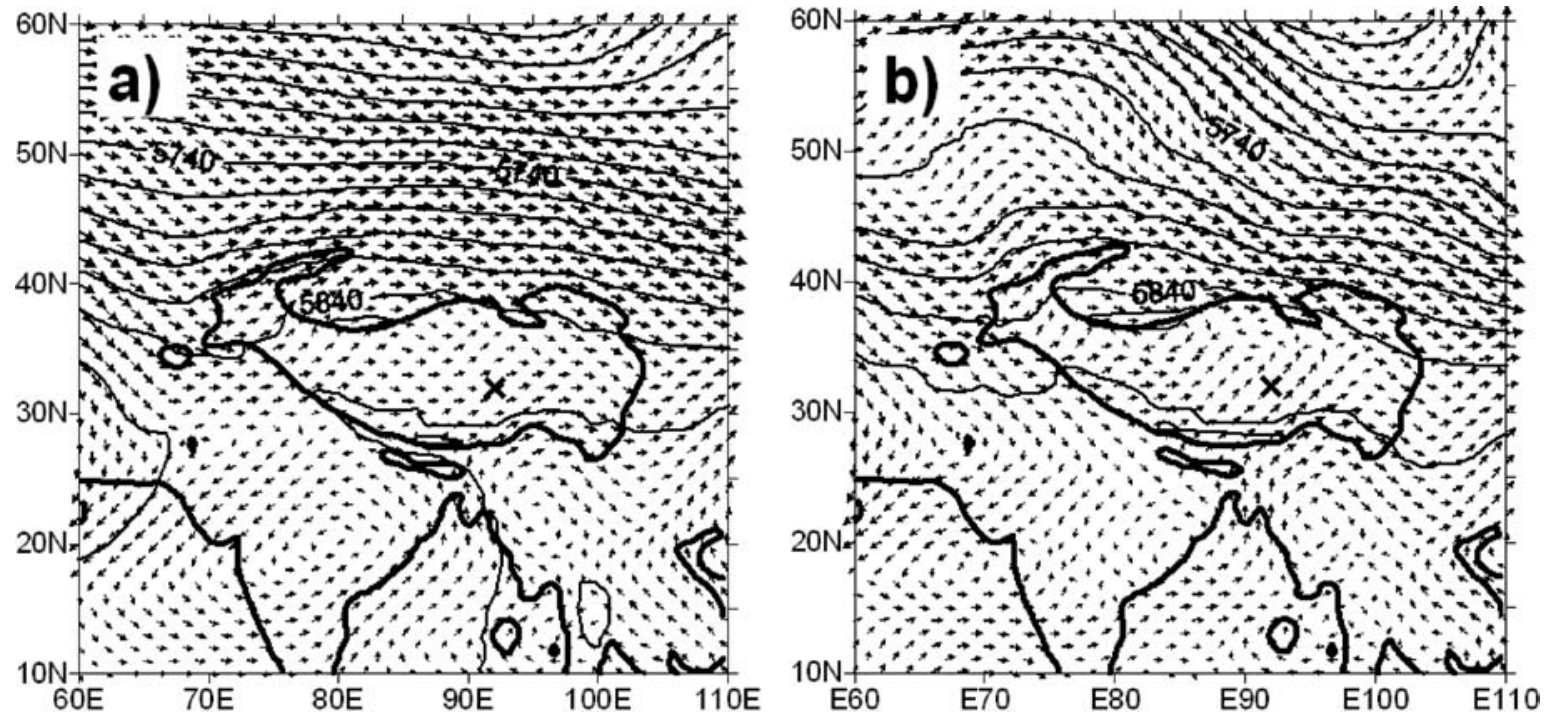

Fig. 5. Average of $500 \mathrm{hPa}$ geopotential height $(\mathrm{m})$ and horizontal wind vectors on GAME reanalysis at 18 UTC from July to August 1998 (left) and the same only but for 16 days of PME used in Fig. 3 (right). A cross indicates the location of the Naqu basin. The 3,000 $\mathrm{m}$ a.s.l. and the coastal line are illustrated.

northeastern TP accompanied with a mid-latitude trough in the northeast. Yamada and Uyeda (2006) classified rain events during the 1998 mon- soon into three types based on the preference of the synoptic scale trough and upper high (Tibetan anticyclone) over the plateau. However, the occur- 
a) June 1718 UTC

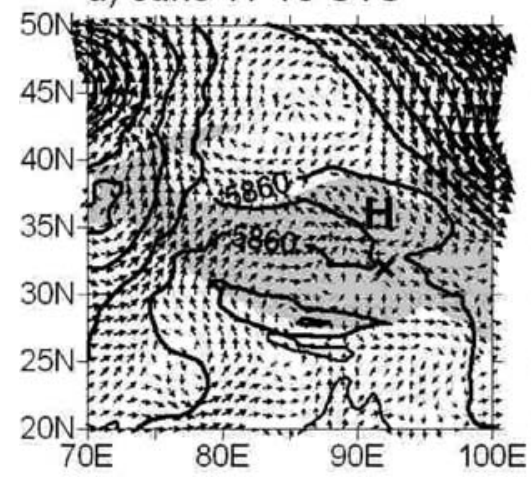

C) July 2918 UTC

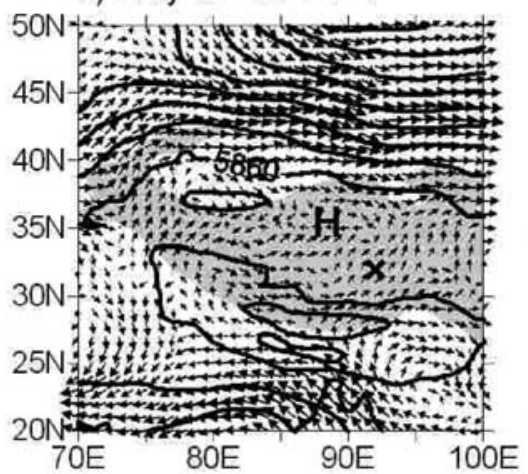

e) Aug. 918 UTC

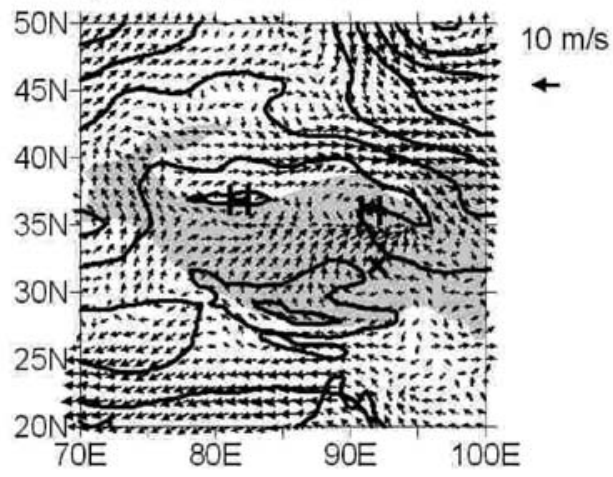

b) July 2118 UTC

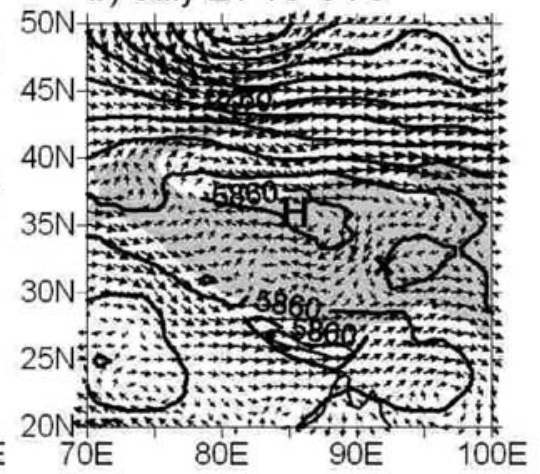

d) Aug. 118 UTC

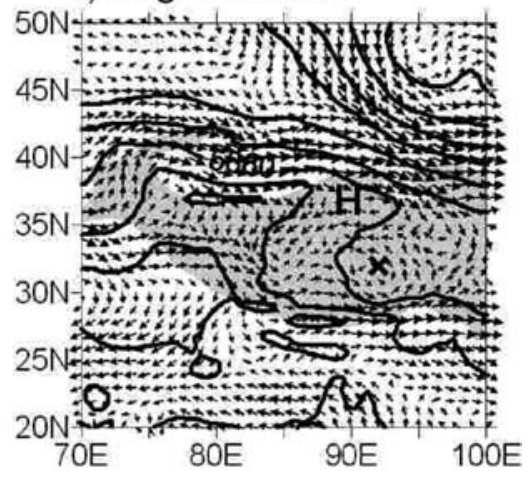

$\mathrm{m} / \mathrm{s}$

Fig. 6. Five cases of geopotential height $(\mathrm{m})$ and wind vector at $500 \mathrm{hPa}$ in the GAME reanalysis with the PME prevailing in the Naqu basin. Altitudes in excess of 3,000 $\mathrm{m}$ a.s.l. are shaded, and a cross indicates the location of the Naqu basin.

rence of PME in Table 1 did not show a clear linkage to their classification. This was because wave activity in the north of TP propagated in a shorter time scale than the synoptic scale variability linking to the oscillation of a Tibetan anticyclone (Zhang et al. 2002). In the next section, the role of the synoptic scale flows in the occurrence of PME will be explained for the case of August 1-2, which was also intensively diagnosed by Shimizu et al. (2001).

\section{Case study of PME on August 1-2}

Figure 7 shows METEOSAT-5 IR images taken at 6-hour intervals through the night of August 12. On the evening of August 1 (12 UTC), strong convective activities prevailed on the southern plateau. Isolated cloud area in the north of the TP corresponded with a strong westerly (Fig. 6d) indicating a baroclinic disturbance in the mid-latitudes. 


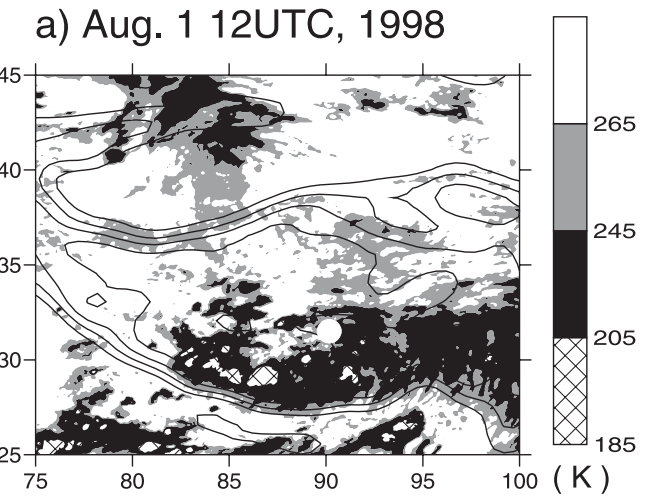

b) Aug. 118 UTC, 1998

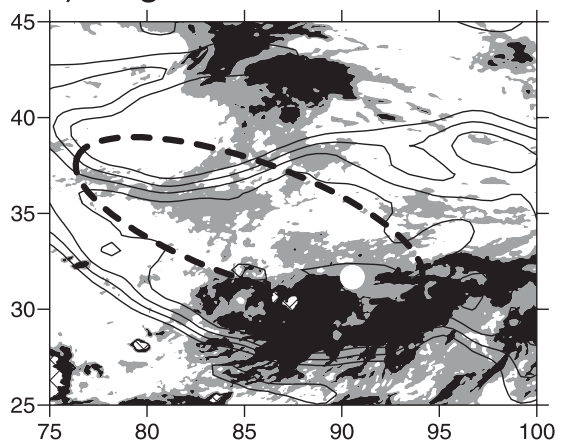

c) Aug. 2 OUTC, 1998

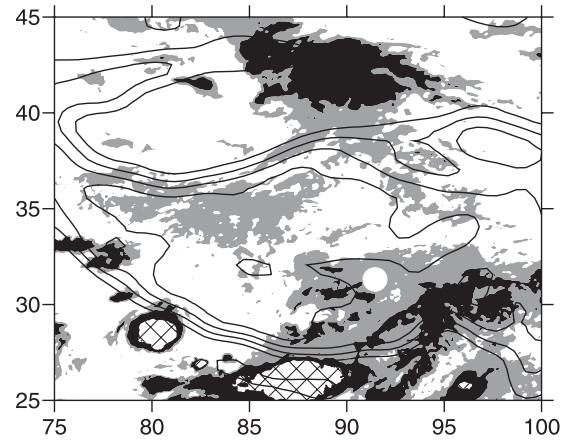

d) Aug. 2 6UTC, 1998

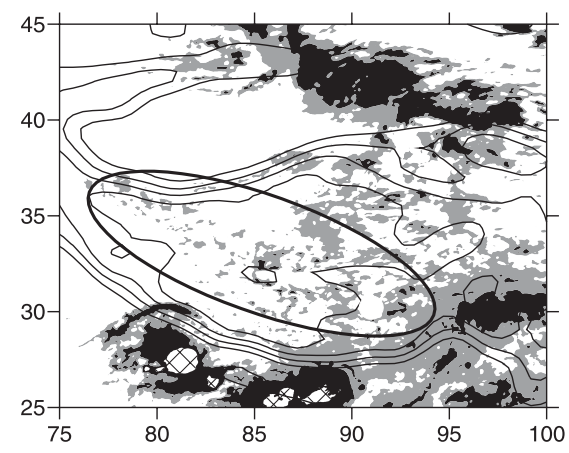

At midnight (18 UTC), zonal stratiform cloud areas with $245-265 \mathrm{~K}$ of brightness temperature appeared in the central TP, stretching in the WNW-ESE direction (marked as a dashed ellipse in Fig. 7b). The ESE end of the zonal cloud area covered the Naqu basin (white circle in Fig. 7b), indicating the occurrence of PME analyzed in the previous section, and agreed with the observation by Shimizu et al. (2001). The cloud zone remained until the morning of August 2 with extending throughout the areas. It then became deformed with the start of the morning mesoscale thermal convection (marked as a solid ellipse in Fig. 7d).

A numerical simulation was performed in the domain shown in Fig. 1 to diagnose the mechanism of cloud zone formation. Figure 8 shows the simulated $500 \mathrm{hPa}$ geopotential height anomaly (left) and cloud water plus cloud ice (right) with wind vectors at the same times of Fig. 7. At 12 UTC (Fig. 8a), westerlies in the mid-latitude were divided into two routes at the northwestern edge of the plateau (the tail of the TP). One route flowed along $40^{\circ} \mathrm{N}$ and turned east-southeast over the northeast to follow a trough, and the other flowed along the southwestern edge of the TP, causing a westerly flow over the southeastern TP areas. Between those two flows, a wind convergence zone was formed running in the WNW-ESE direction over the central plateau, accompanying the anticyclonic circulations in the north. Mesoscale cloud formation was simulated along the zone (shown in blue on the right of Fig. 8a). The anticyclonic circulation accompanied an easterly wind component corresponding with the feature of the GAME reanalysis (Fig. 6). At midnight (18 UTC, Fig. 8b), clouds along the convergence zone developed more, and low-pressure anomaly area with cyclonic circulation was formed at the central plateau surface. In the early morning (0 UTC, Fig. 8c), the convergence zone shifted southeastward, and cloud areas extended with a more intensive and isolated lowpressure anomaly.

Longitudinal cross sections of the wind field and equivalent potential temperature along $32.5^{\circ} \mathrm{N}$ are

Fig. 7. METEOSAT IR images at 12 and 18 UTC on August 1 and 0 and 6 UTC on August 2. The location of the Naqu basin is marked as a white circle. Dashed and solid ellipses indicate nighttime zonal stratiform cloud areas and their daytime traces, as explained in the Section 4. 

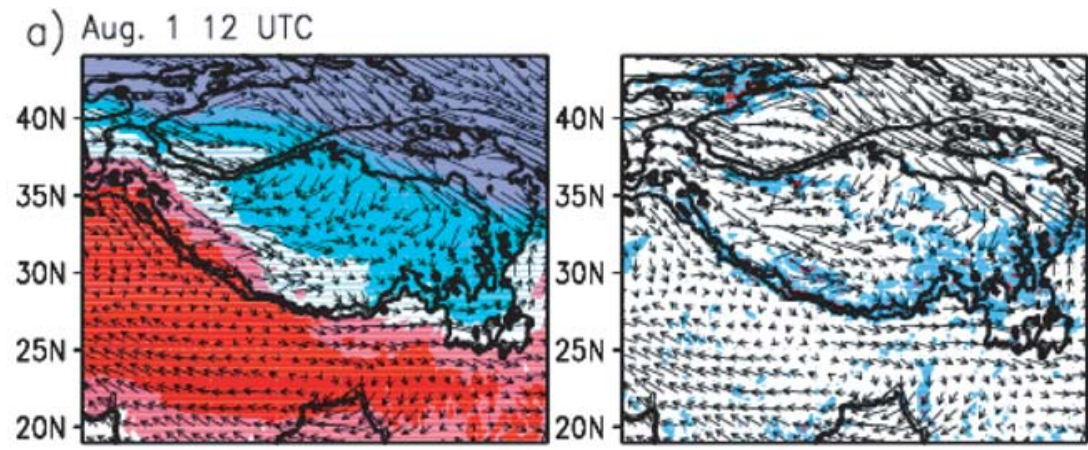

b) Aug. 118 UTC
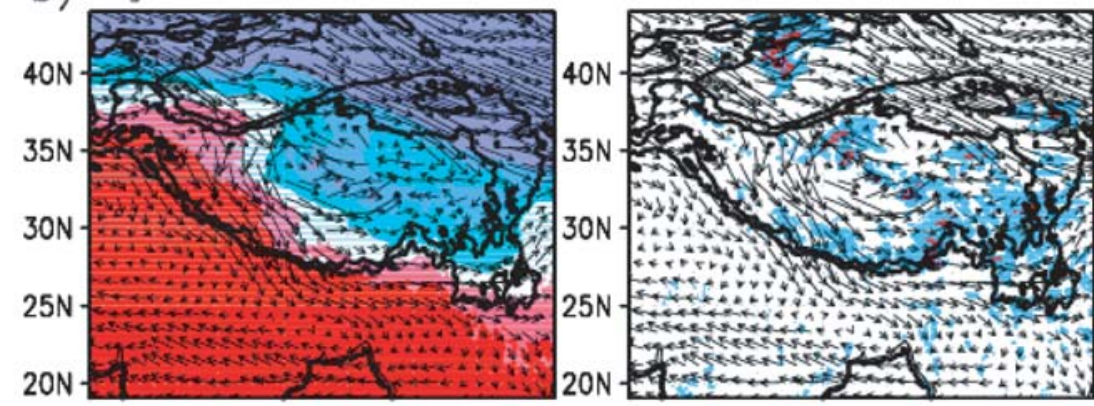

c) Aug. 20 UTC
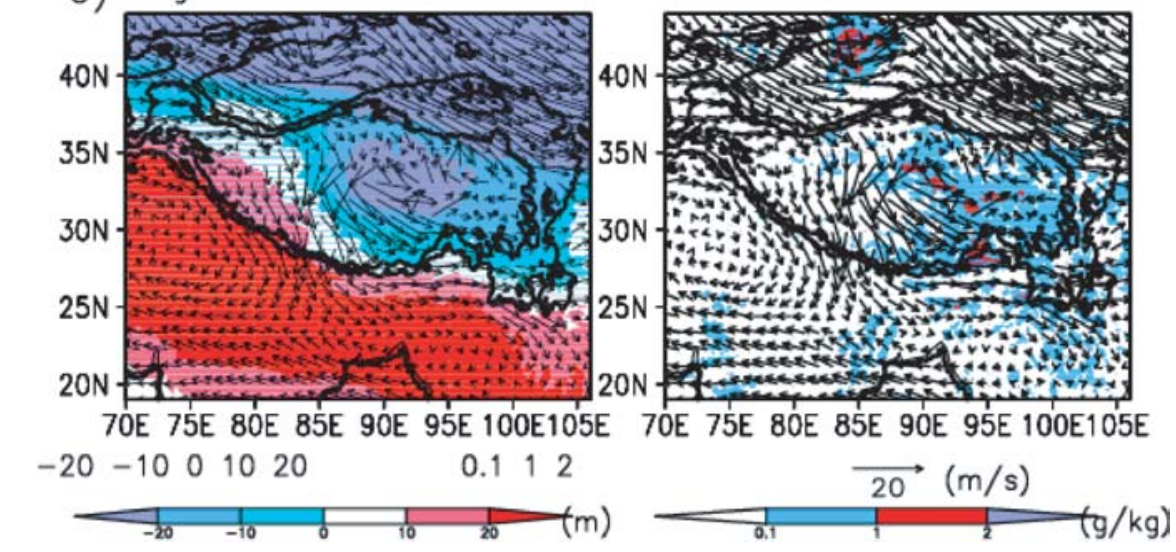

Fig. 8. Wind vector with geopotential height anomaly (left) and with amount of cloud plus cloud ice (right) at $500 \mathrm{hPa}$ simulated by the WRF model on August 1. The geopotential anomaly is a deviation from the daily average on August 1 of the domain. The contour lines at 2,000 and 4,000 $\mathrm{m}$ a.s.l. are drawn.

shown in Fig. 9 to diagnose the evolution of the convergence zone. In the early night of August 1 (12 UTC), convective instability layers existed below $400 \mathrm{hPa}$ in the central domain, and a weak easterly wind below $450 \mathrm{hPa}$ was recognized in the eastern portion that intruded under the deep westerlies. The vertical distribution of the equivalent potential temperature observed at the Amdo site at the same time (Fig. 10, left) also showed weak convective instability below $450 \mathrm{hPa}$ with easterly flows at the bottom (Fig. 4), indicating that the WRF simulation corresponded well with the actual feature of atmospheric instability and low-level flows in the beginning of the convergence. An increase in the equivalent potential temperature at the near-surface level was due to an increase of moisture at night, as was observed by Kuwagata et al. (2001). At 18 UTC, a low-level wind convergence activated cloud development using the instability, and then the instability layer started 
a) Aug. 112 UTC

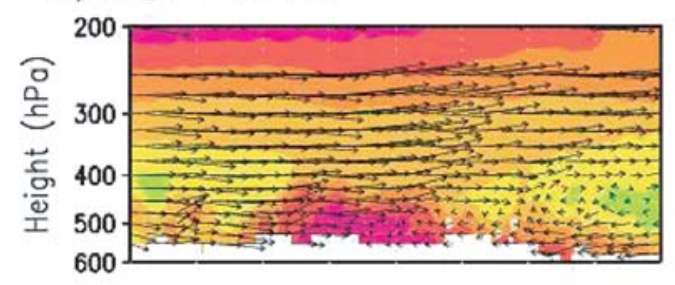

b) Aug. 118 UTC

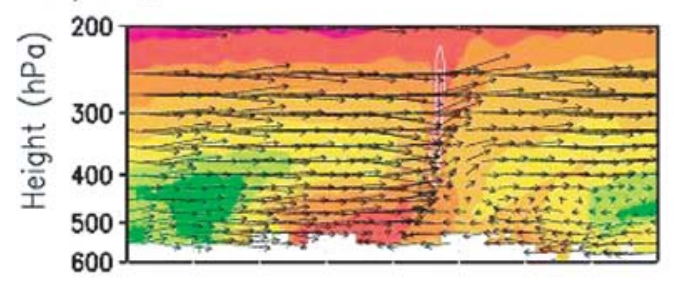

c) Aug. 2 O UTC

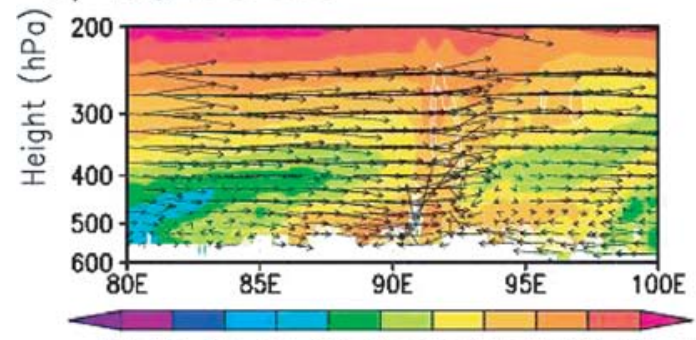

$\begin{array}{llllllllllll}327 & 330 & 333 & 336 & 339 & 342 & 345 & 348 & 351 & 354 & 357 & (K)\end{array}$

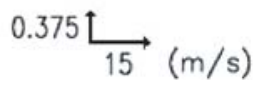

Fig. 9. Cross section of equivalent potential temperature and wind vectors in the longitude-vertical ( $\mathrm{u}, \mathrm{w})$ component along $32.5^{\circ} \mathrm{N}$. The white areas are the surface topography.

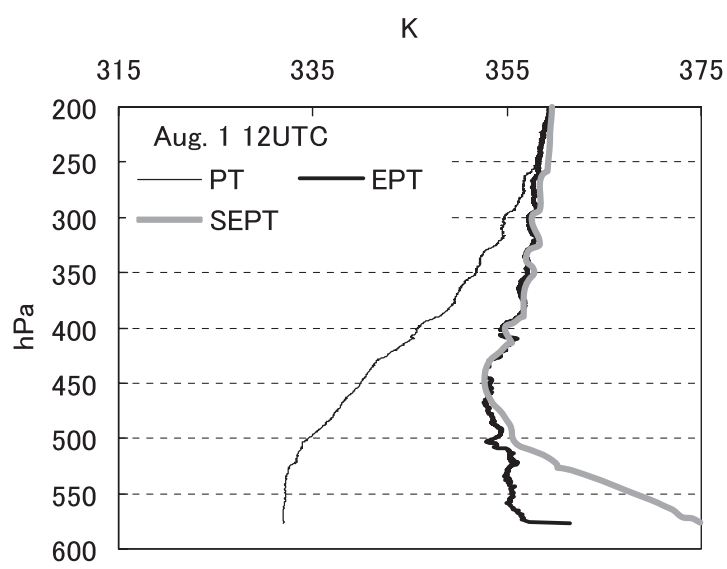

to dissipate with the development of the cloud area, as shown on the right in Fig. 8c. Namely, the synoptic-scale convergence flow was an important trigger for the activation of convection using the nighttime low-level convective instability and resulted in the start of PME.

The simulation was performed with different conditions, such as cutting off the latent heat flux at the ground (NoFLUX) without condensation in the atmosphere (NoCOND) and changing the topography to one half of the elevation (HTOP), to reveal the cause of synoptic scale convergence flows. Results at 18 UTC of August 1 are compared with the original simulation run (Fig. 8b) at the same elevation $(500 \mathrm{hPa})$ for NoFLUX and NoCOND and at the $700 \mathrm{hPa}$ (near-surface level of the plateau) for HTOP in Fig. 11. Wind convergence still occurred for the cases of NoFLUX and NoCOND (Fig. 11a,b), but it disappeared at $500 \mathrm{hPa}$ in the case of HTOP (figure omitted). At $700 \mathrm{hPa}$ for the case of HTOP (Fig. 11c), similar but more enhanced anticyclonic circulation appeared with its center over the northern periphery of TP inducing a strong easterly along $32.5^{\circ} \mathrm{E}$. The results indicated that the cause of low-level convergence in the central TP was fundamentally due to the dynamic effect of the plateau topography. The slopes forming northern and northwestern edge of the plateau caused stagnation of the northwesterly winds flowing in the west of a trough, which resulted in the convergence of atmosphere near the surface on the plateau. In the case of NoCOND (Fig. 11b), zonal wind convergence running in the central TP (Fig. 8b) became ambiguous, and a cy-

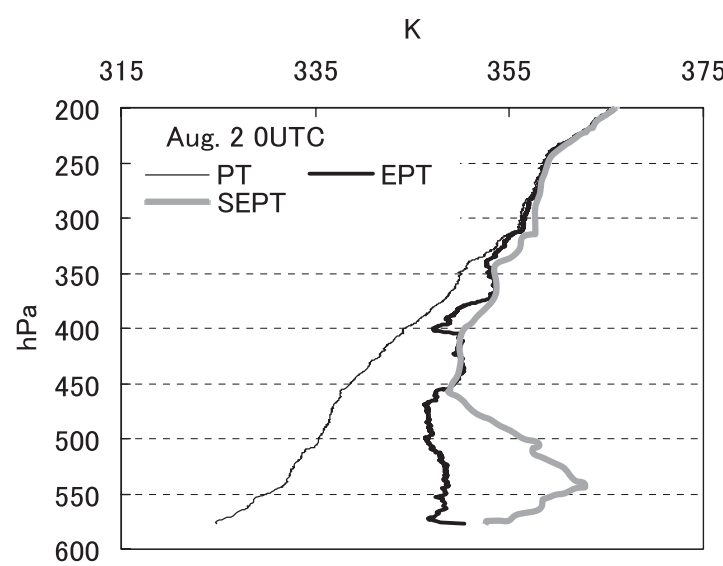

Fig. 10. Vertical distributions of potential temperature (PT), equivalent potential temperature (EPT), and saturated equivalent potential temperature (SEPT) calculated by Amdo sonde data. 

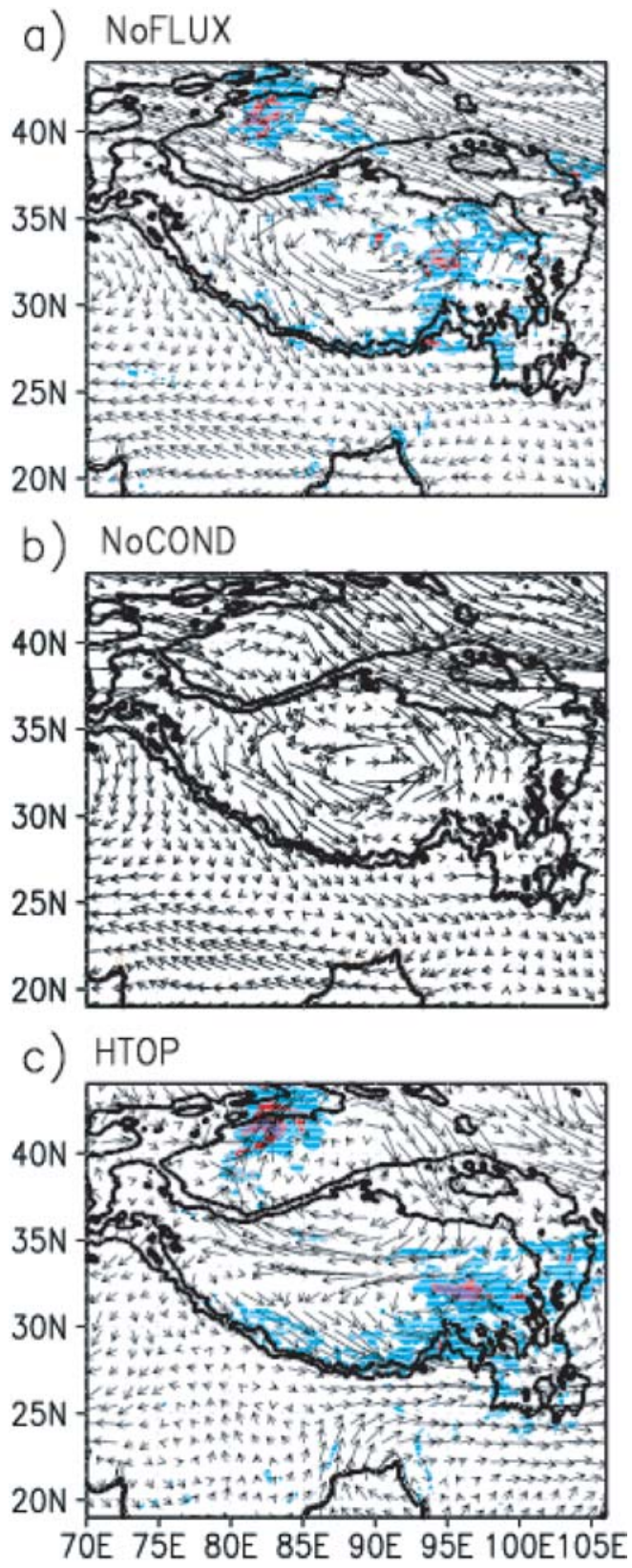

$20 \quad(\mathrm{~m} / \mathrm{s})$

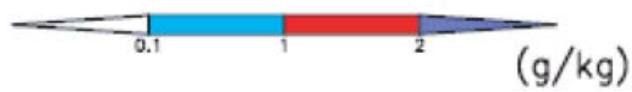

Fig. 11. Sensitivity experiments by the WRF model in cases of a) no latent heat flux on the ground (NoFLUX), b) no condensation in the atmosphere (NoCOND) at the $500 \mathrm{hPa}$ level, and c) changing the topography to the half of elevation (HTOP) at clonic circulation dominated and shifted the convergence northward. NoFLUX showed an intermediate feature between NoCOND and the original run. Accordingly, sensible heating in the lower troposphere intensified the formation of the convergence zone while changing the location that affected the PME distribution within the TP in the numerical simulations.

\section{Summary and discussions}

Midnight to early morning precipitations occurred frequently in the 1998 monsoon at central TP and was analyzed with observational data and WRF numerical simulations. In the reanalysis data, many of the cases were accompanied with easterly component winds near the surface of the plateau in the northeast of the TP after passing a synoptic scale trough in the mid-latitudes, which corresponded with observational evidence. A numerical model successfully simulated a convergence zone near the surface of the plateau and the development of a precipitation system by using nighttime convective instability at the lower troposphere. Sensitivity studied by the simulation revealed that the dynamical effect of the TP topography induced the stagnation to the northwesterly general flows associated with a mid-latitude trough and caused the convergence over the central TP. The simulation also raised the possibility that latent heat release in the atmosphere determines the location of the PME system within the plateau. The mechanism of establishing the PME system is unique compared to those in previous studies, in which the cause of nighttime precipitation in Asia had been attributed to the propagation of a squall line from the mountains or contribution of local circulations. Usually, monsoon precipitation prevails in the southern or southeastern areas of the TP, but the convergence zone with PME has a function to extend the precipitation areas westward and will contribute to moisten the semi-arid areas. Fujinami and Yasunari (2004) reported that the variability of convections on timescales of 14 days was notable in 1998 in association with well-developed wave trains along the Asian subtropical jet. The preference of the PME during the monsoon season is

the $700 \mathrm{hPa}$ level, at $18 \mathrm{UTC}$ of August 1. Contours and hatches are the same for Fig. 8 , except for the contours in c) at 1,000 and 2,000 $\mathrm{m}$ a.s.l., respectively. 
expected to depend on the year-to-year variability of continental scale sub-monthly oscillation. There are two points to be discussed regarding the precipitation mechanism diagnosed in this study. One is the reason for the domination of the precipitation system in the nighttime. The other is the discrepancy between the simulated feature and observations.

The synoptic pattern in the mid-latitudes usually continues for several days and does not limit the nighttime occurrence. Therefore, so it is a necessary condition, but it cannot explain the dominance of nighttime precipitation. In the daytime, mesoscale convection prevails due to strong surface heating during the monsoon season, especially that organized by the mountain ranges in the plateau (e.g. Kurosaki and Kimura 2002). The cloud image at 6 UTC on August 2 (Fig. 7d) shows this characteristic, namely, that isolated convection in the mesogamma scale has initiated before noon. METEOSAT images quite often showed such development of smaller-scale isolated clouds during 8:00-13:00 LT over the TP but not in the evening and nighttime. Upon careful examination of the location of clouds, it was noticed that they were still aligned in the WNW-ESE direction (marked by a solid ellipse in Fig. 7d), which assured that synoptic-scale convergence had endured into the morning. Namely, synoptic scale convergence in the daytime was disturbed by the development of thermal convection initiated by the topography or local circulations due to strong surface heating, and the precipitation zone due to the convergence was only enhanced during the night. Especially, daytime precipitation in the Naqu basin tends to be smaller due to local suppressions affected by the convections over surrounding mountains. Kuwagata et al. (2001) attributed the cause of increasing nocturnal low-level moisture to diurnal changes of local circulations, especially in the pre-monsoon season. Our simulation showed that a low-level moist atmosphere distributed widely over the plateau in the early evening. This was because, in the case study, it was in the core of monsoon season when the plateau surface was already wet and the latent heat flux had dominated over the sensible heating (Tanaka et al. 2001). We assume that a stable but relatively humid low-level atmosphere potentially exists over the plateau in the nighttime after the monsoon matures, which provides a favorable condition to start convection by the synoptic-scale trigger. In fact, many of the PME cases occurred in the middle and late monsoon season (Table 1), which supports this idea.

Results of the WRF simulation did not agree in detail with observational evidence. The convergence zone with easterly flows by the WRF simulation was located several degrees northeast of the Naqu basin. The observed cloud structure by radar echoes at the Naqu basin and METEOSAT images indicated a rather stratified system, but the WRF simulated deep convection along the cross section of the convergence zone. According to the sensitivity study of the WRF simulation, the location of the trough and convective system differed between the dry and moist runs. When the convective system was simulated in the south, a greater intrusion of moisture from the south of the TP enhanced the cloud development in the model. Recently, Sato et al. (2008) pointed out that finer scale is necessary to simulate realistic phase of the precipitation diurnal cycle during the spring season over the TP. Therefore, simulating an accurate location and structure of convections within the TP requires accurate information of low-level moisture distribution with finer resolution scale and precise heterogeneous land-surface data as the initial boundary condition. Adopting the Kain-Fritsch convective parameterization for the nighttime atmosphere over the TP should also be verified by radar observations at more convective areas. We also speculate that the fish-tail shape of the northwestern plateau topography plays an important role to change the general flow pattern over the TP intruding from mid-latitude, and sensitivity study with different conditions of plateau shape and stability are expected.

In this paper, we provide an explanation for the occurrence of PME in the central TP only and not throughout the plateau. The different direction of the incoming general flows would cause convergences in various areas. Nighttime precipitation affected by the local mountain-valley circulation would also dominate in the southern plateau areas. The establishment of radar observation and gauge network over the TP would clarify the wider behavior of the PME distribution to achieve a better implication of the TP thermal effects and water budgets for glaciers.

\section{Acknowledgments}

This study was conducted with support from the Core Research for Evolutional Science and Technology of the Japan Science and Technology 
Agency. This is also a preliminary study for CEOP Coordinated Asia-European long-term Observing system of Qinghai/Tibet Plateau hydrometeorological processes and the Asian-monsoon system with Ground satellite Image data and numerical Simulations project (AEGIS, No. FP7ENV-2007-1212921) funded by the European Commission, coordinated by Professor M. Menenti of the University Louis Pasteur in France. The authors are grateful again to all the participants of the GAME-Tibet project which could successfully provide the unique in-situ data even in the severe field conditions.

\section{References}

Barros, A., and T. Lang, 2003: Monitoring the monsoon in the Himalayas: Observations in central Nepal, June 2001. Mon. Wea. Rev., 131, 1408-1427.

Bhatt, B. C., and K. Nakamura, 2005: Characteristics of monsoon rainfall around the Himalayas revealed by TRMM precipitation radar. Mon. Wea. Rev., 133, 149-165.

Chen, F., and J. Dudhia, 2001: Coupling an advanced land-surface/hydrology model with the Penn State/ NCAR MM5 modeling system. Part 1: Model description and implementation. Mon. Wea. Rev., 129, 569-585.

Choi, T. J., J. K. Hong, J. Kim, H. C. Lee, J. Asanuma, H. Ishikawa, G. Zhiqiu, Y. Ma, J. Wang, T. Koike, T. Yasunari, K. Ueno, and O. Tsukamoto, 2004: Turbulent exchange of heat, water vapor and momentum over a Tibetan prairie by eddy covariance and flux-variance measurements. $J$. Geophys. Res., 109, D21106, doi:10.1029/ 2004JD004767.

Clark, C. A., and R. W. Arritt, 1995: Numerical simulations of the effect of soil moisture and vegetation cover on the development of deep convection. $J$. Appl. Meteor., 34, 2029-2045.

Findell, K. L., and E. A. B. Eltahir, 2003: Atmospheric controls on soil moisture-boundary layer interactions. Part II: Feedback within the continental United States. J. Hydrometeor., 4, 570-583.

Fujinami, H., and Y. Yasunari, 2004: Submonthly variability of convection and circulation over and around the Tibetan Plateau during the boreal summer. J. Meteor. Soc. Japan, 82, 1545-1564.

Fujinami, H., S. Nomura, and T. Yasunari, 2005: Characteristics of diurnal variation in convection and precipitation over the southern Tibetan Plateau during summer. SOLA, 1, 49-52.

Higuchi, K., 1977: Effect of nocturnal precipitation on the mass balance of the Rikha Samba Glacier, Hidden Valley, Nepal. Journal of the Japanese Society of Snow and Ice, 39, 43-49.
Kain, J. S., and J. M. Fritsch, 1993: Convective parameterization for mesoscale models: The Kain-Fritsch scheme. The representation of cumulus convection in numerical models. Meteor. Monogr., No. 24, Amer. Meteor. Soc., 165-170.

Kalnay, E., M. Kanamitsu, R. Kistler, W. Collins, D. Deaven, L. Gandin, M. Iredell, S. Saha, G. White, J. Woollen, Y. Zhu, A. Leetmaa, B. Reynolds, M. Chelliah, W. Ebisuzaki, W. Higgins, J. Janowiak, K. C. Mo, C. Ropelewski, J. Wang, R. Jenne, and D. Joseph, 1996: The NCEP/NCAR 40-Year Reanalysis Project. Bull. Amer. Meter. Soc., 77, 437471.

Kataoka, A., and T. Satomura, 2005: Numerical simulation on the diurnal variation of precipitation over northern Bangladesh: A case study of an active period 14-21 June 1995. SOLA, 1, 205-208.

Kurosaki, Y., and F. Kimura, 2002: Relationship between topography and daytime cloud activity around Tibetan Plateau. J. Meteor. Soc. Japan, 80, 1339-1355.

Kuwagata, K., A. Numaguti, and N. Endo, 2001: Diurnal variation of water vapor over the central Tibetan Plateau during summer. J. Meteor. Soc. Japan, 79, 401-418.

Sato, T., T. Yoshikane, M. Satoh, H. Miura, and H. Fujinami, 2008: Resolution dependency of the diurnal cycle of convective clouds over the Tibetan Plateau in a mesoscale model. J. Meteor. Soc. Japan, $\mathbf{8 6 \mathbf { A }}$, 17-31.

Satomura, T., 2000: Diurnal variation of precipitation over the Indo-China peninsula: Two-dimensional numerical simulation. J. Meteor. Soc. Japan, 78, 461-475.

Shimizu, S., K. Ueno, H. Fujii, H. Yamada, R. Shirooka, and L. Liu, 2001: Mesoscale characteristics and structures of stratiform precipitation on the Tibetan Plateau. J. Meteor. Soc. Japan, 79, 435461.

Skamarock, W. C., J. B. Klemp, J. Dudhia, D. O. Gill, D. M. Barker, W. Wang, and J. G. Powers, 2005: A Description of the Advanced Research WRF Version 2, NCAR Technical Note, NCAR/ TN-468+STR, $88 \mathrm{pp}$

Tanaka, K., H. Ishikawa, T. Hayashi, I. Tamagawa, and Y. Ma, 2001: Surface energy budget at Amdo on the Tibetan Plateau using GAME/Tibet IOP98 data, J. Meteor. Soc. Japan, 79, 505-517.

Tripoli, G. J., and W. R. Cotton, 1989: Numerical study of an observed orogenic mesoscale convective system. Part 1: Simulated genesis and comparison with observation. Mon. Wea. Rev., 117, 273-304.

Tucker, D. F., and N. A. Crook, 1999: The generation of a mesoscale convective system from mountain convection. Mon. Wea. Rev., 127, 1259-1273.

Ueno, K., 1998: Characteristics of plateau-scale precipi- 
tation in Tibet estimated by satellite data during 1993 monsoon season. J. Meteor. Soc. Japan, 76, 633-548.

Ueno, K., H. Fujii, H. Yamada, and L. Liu, 2001: Weak and frequent monsoon precipitation over the Tibetan Plateau. J. Meteor. Soc. Japan, 79, 419-434.

U.S. Geological Surveys, 2000. GTOPO30-Global topographic data. http://edcdaac.usgs.gov/gtopo30/ gtopo30.html.

Uyeda, H., H. Yamada, J. Horikomi, R. Shirooka, S. Shimizu, L. Liu, K. Ueno, H. Fujii, and T. Koike, 2001: Characteristics of convective clouds observed by a Doppler Radar at Naqu on the Tibetan Plateau during the GAME-Tibet IOP. J. Meteor. Soc. Japan, 79, 463-474.

Yamada, H., and H. Uyeda, 2006: Transition of the rainfall characteristics related to the moistening of the land surface over the central Tibetan Plateau during the summer of 1998. Mon. Wea. Rev., 134, $3230-3247$.
Yamada, H., 2008: Numerical simulations on the role of land surface conditions in the evolution and structure of summer thunderstorm over a flat highland. Mon. Wea. Rev., 136, 173-188.

Yamazaki, N., K. Takahashi, and A. Yatagai, 2003: Report on the GAME reanalysis. GAME (GEWEX Asian Monsoon Experiment) phase 1 summary report, $81-87$.

Yanai, M. and G. X. Wu, 2006: Effects of the Tibetan Plateau. The Asian Monsoon, B. Wang, Ed., Springer, 513-549.

Yang, K., T. Koike, H. Fujii, T. Tamura, X. Xu, L. Bian, and M. Zhou, 2004: The daytime evolution of the atmosphere boundary layer and convection over the Tibetan Plateau: Observations and simulations. J. Meteor. Soc. Japan, 82, 1777-1792.

Zhang, Q., G. Wu, and Y. Qian, 2002: The bimodality of the $100 \mathrm{hPa}$ south Asia high and its relationship to climate anomaly over East Asia in summer. $J$. Meteor. Soc. Japan, 80, 733-744. 